HISTORY OF MEDICINE

\title{
Genitourinary medicine and surgery in Nelson's navy
}

\section{J C Goddard}

Postgrad Med J 2005;81:413-418. doi: 10.1136/pgmj.2004.022335

Surgeons of the Royal Navy during the Napoleonic and revolutionary wars, between 1793 and 1815, were solely responsible for all health care of the officers, men, and boys of their ships. This paper examines the genitourinary medicine and surgery encountered by the naval surgeons at the time of Nelson. Primary sources are examined to explore the presentation, case mix, and management of genitourinary disease during this period. A general overview is given of the life and work of the Royal Naval surgeons at the end of the 18th century. The documents that were examined contained 39 surgeon's journals, these were written by 26 surgeons on 13 different ships. The journals contained 446 presentations to the sick list of men with genitourinary symptoms. The presenting symptoms are grouped together under the following headings; venereal disease, penile pathology, scrotal pain and swelling, urinary symptoms and retention, stone disease and trauma. Examination of these journals permits a glimpse of medical life in the Royal Navy during the time of Nelson. The case load and management of genitourinary disease shows the diversity of presentation to these surgeons.
Correspondence to: Mr J C Goddard, Department of Urology, University Hospitals of Leicester NHS Trust, Leicester General Hospital, Gwendolen Road, Leicester LES 4PW, UK; jonathan@jcgoddard. freeserve.co.uk

Submitted 14 April 2004 Accepted 23 June 2004
S urgeons of the Royal Navy during the Napoleonic and revolutionary wars, between 1793 and 1815, were solely responsible for all health care of the officers, men, and boys (and usually women) of their ship. On land there was a tripartite split in the medical profession at the time. The physicians, who were allowed to call themselves doctor, held a medical degree and were members of the elite College of Physicians. They treated internal disease based on classical principles. The apothecaries, in London governed by Apothecaries' Hall, were the nearest equivalent to today's general practitioners. They dispensed medicines to treat most ailments. The surgeons were skilled in treating external ailments; boils, sprains, and fractures. They performed the few operations of the time, for example, amputations and rarely cutting for the stone. The naval surgeon however, was alone on his ship and was required to take the place of all three practitioners, treating not just surgical ailments but taking on any and all medical problems that presented.

This paper examines the genitourinary medicine and surgery encountered by the naval surgeons at the time of Nelson. Primary sources are examined to explore the presentation, case mix, and management of genitourinary disease during this period. A general overview is given of the life and work of the Royal Naval surgeons at the end of the 18th century.

\section{THE 18TH CENTURY NAVAL MEDICAL SERVICE}

The naval surgeons of the Nelsonian period have an undeserved reputation as rough "sawbones" only able to hack off limbs and pull teeth. Indeed, at the time, Sir William Dillon said of his surgeon, Thomas Grey, "Although an excellent scholar, being nearsighted with a defect in one of his eyes-we did not place much reliance on his ability at amputation." Contemporary accounts such as this one do little for the surgeons' reputation. There is ample evidence however, to suggest that at least some naval surgeons were well educated and qualified in their field. They were men of science who strived to better their profession and the lot of their patients. ${ }^{12}$

To become a naval surgeon in the 18th century, an apprenticeship was first served with a practising surgeon ashore. Time could then be spent in a university or local hospital to learn the basics of anatomy, physic, and pharmacology. Few matriculated however and once they had gained sufficient knowledge, they proceeded to the College of Surgeons, in London, for examination.

The diary of surgeon Peter Cullen contains a contemporary description of this examination, ${ }^{3}$ held at Surgeon's Hall, Old Bailey, near Newgate, at seven o'clock in the evening on the 3 December 1789. Cullen, we are told, "made himself thoroughly acquainted with every surgical question or case that could possibly be propounded to him and went confidently in .... the examiner proceeded to question him on anatomy, physiology and surgery [and] some of the more important surgical cases or diseases, and how he would treat them. This Gentleman was quite satisfied with Mr. Cullen's proficiency, and taking him up to the centre of the table, where the president bowed to Mr. Cullen, and desired him to pay one guinea as a fee."

The Court of Examiners of the College of Surgeons would tell the navy at what level the newly qualified surgeon could serve in His Majesty's ships. Only the best could be a full ship's surgeon, most became a surgeon's mate, first, second, or third class. Furthermore, the rate or size of ship was also specified. The college also had the privilege of specifying which instruments were to be provided and examined the instrument chests before each voyage. Surgeons (at least at the beginning of the war) were obliged to buy their own instruments and chest of medicines. ${ }^{4}$ 
On board ship, the operating area (and often the surgeon's cabin as well), was found on the Orlop deck (fig 1). This was below the waterline, dark and stuffy and fouled by the air coming off the bilges. The low deck height forced the surgeon into a constant stoop. It was however, a comparatively safe area during a sea battle. Although, with the massive 32 pounder guns of the lower gun deck thundering above the surgeon's head, it was not necessarily the most peaceful working environment. When the ship was not in action, the sickbay was usually situated on a higher deck, often in a partitioned area with more light and air. Most patients who feature in this paper would have been treated here.

\section{METHODS AND RESEARCH SOURCES}

Naval surgeons at this time were obliged to provide both the Admiralty and the College of Surgeons with a detailed medical journal of every voyage. There are, unfortunately, precious few of these extant. Nevertheless, those that remain give a first hand account of contemporary medical and surgical practice.

The surgeons' journals examined for this paper are kept at the Public Record Office, Kew, United Kingdom. In total, there are 121 bundles of documents dating from the period 1793 to 1815. The data in this paper are taken from the examination of 15 of these bundles. The bundles are labelled alphabetically with the name of the first ship and thus represent a random selection of surgeons' journals. The journals follow a standard layout; most begin with the name of the ship, where it was stationed, and the time period covered by the journal (fig 2 ). The pages are divided vertically into six sections headed:

- "Mens Names, Ages and Qualities",

- "When and Where put on the Sick List",

- "Statement of the Case when put on the List",

- "Symptoms and Treatment while under Cure",

- "When discharged to Duty, Died or sent to the Hospital"

- "Remarks".

A summary is given at the end of most journals containing the numbers of patients seen with each complaint (table 1).

There are also surgical textbooks dating from the period, written specifically for (and often by) naval surgeons (table 2). In this paper both of these sources have been examined. The textbooks give an indication of what the surgeons could expect in the way of genitourinary disease on these ships and also examples of contemporary management. The primary sources, the journals, record what genitourinary disease was actually encountered, and how it was managed.

\section{THE CONTENTS OF THE JOURNALS}

The 15 bundles of documents that were examined contained 39 surgeon's journals, these were written by 26 surgeons on 13 different ships. The journals contained 446 presentations to the sick list of men with genitourinary symptoms.

The ships were rated by size and number of guns, from the huge first rate man-o-war like HMS Victory with 104 guns, down to little cutters or transports with as few as two guns. With this knowledge it is possible to estimate the number of

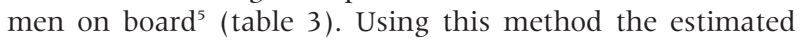
total number of men cared for by the surgeons on the ships in this study was 6555 .

The journals commonly, but not always, spanned one year. The median duration of journals was 364 days (18695 days). In 223 cases, the age of the patients was given, the median age of these was 25 years (15-52 years). Of the total 446 genitourinary medical and surgical cases, 284 involved ordinary or able seamen, 59 marines, 12 petty officers, 15 officers, and 30 idlers (non-seamen such as cooks, clerks, etc).

In 403 cases, the dates of addition to and discharge from the sick list were recorded. The median length of time spent on the sick list with a genitourinary disorder was 22 days (1172 days). The patient who remained on the sick list for the longest was Able Seaman William Flood. He had a venereal ulcer in the groin. This proved difficult to treat and he was eventually discharged to hospital. ${ }^{6}$

The presenting symptoms follow quite closely what would have been expected from looking at the textbooks. They are grouped together under the following headings for ease of discussion; venereal disease, penile pathology, scrotal pain and swelling, urinary symptoms and retention, stone disease, and trauma. As will become clear, these are not mutually exclusive.

\section{VENEREAL DISEASE}

Venereal disease was the most common presentation. There were 338 cases that could be directly attributed to venereal disease. At this time, venereal disease was divided simply into gonorrhoea or lux venereal, also known as lues or the French

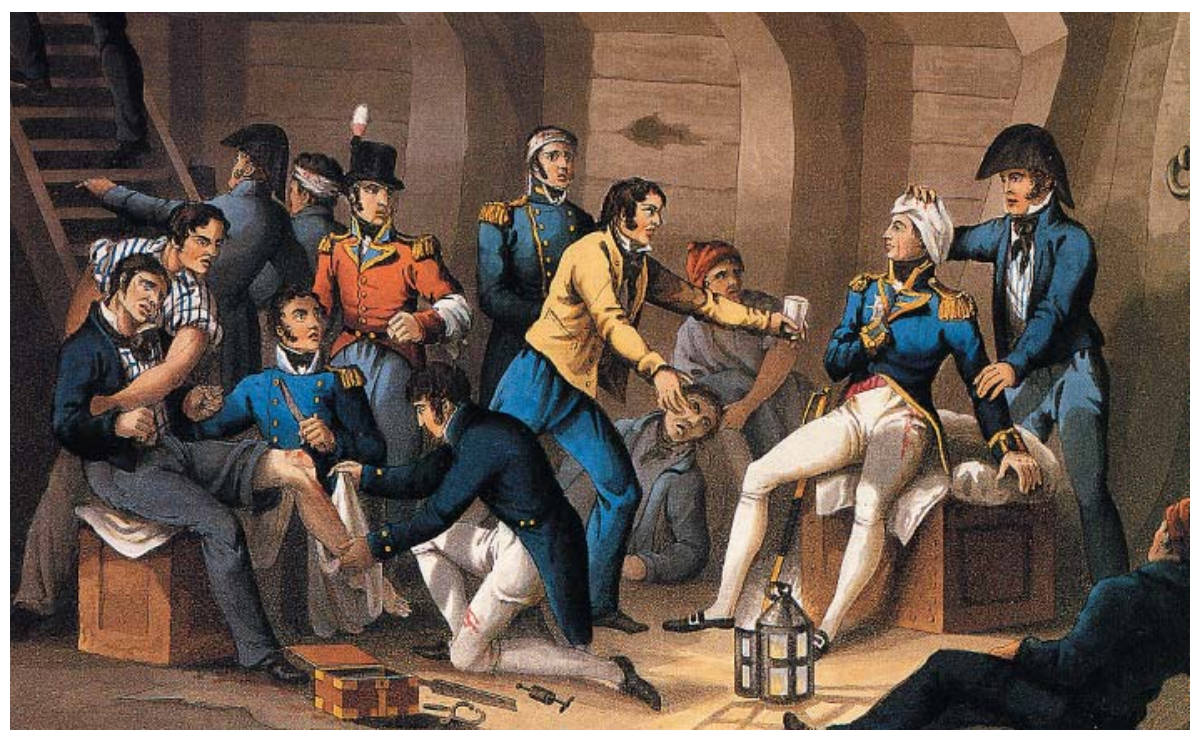

Figure 1 The Cockpit, Battle of the Nile. Unmounted. Produced by Health, William (artist), Dubourg, $M$ (engraver) and Orme, Edward (publisher), 4 Jun 1817. Aquatint, coloured. Height $253 \mathrm{~mm}$, width $351 \mathrm{~mm}$. Museum negative number PU4031). (By permission of the National Maritime Museum). 


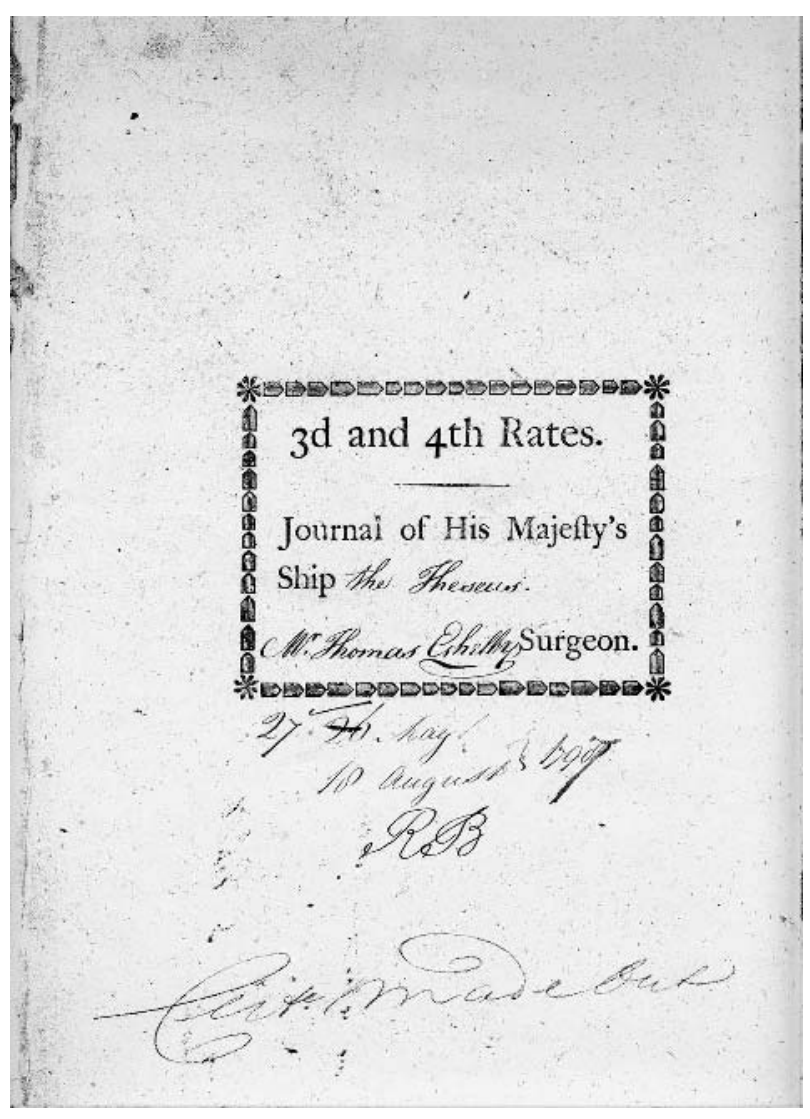

Figure 2 The surgeon's journal of HMS Theseus, 27 May 1797 to 18 August 1798. (Courtesy of the National Archives of the United Kingdom. TNA: PRO ref ADM 101 123/2).

pox, which was syphilis. A confident diagnosis of gonorrhoea was given in 104 cases and of syphilis in 66. The different times of onset of the two diseases were recognised, as was the appearance of secondary symptoms with syphilis. Syphilis was generally treated with mercury as the chloride or iodide salts or as an ointment in suet or lard. This was often applied as a solution called calomel (mercury chloride). Mercury treatments were also called saturine, lunar caustic, or just plain clap balsam.

The sailors presented with multiple symptoms, in 94 cases buboes (swellings, often suppurating, in the groins) were present, in 83 chancres were seen, and in 60 further cases

Table 1 Number of admissions to the sick bay categorised by disease, taken from the journal summaries

\begin{tabular}{ll}
\hline Condition & Number \\
\hline Continuous fevers (for example, typhus) & 342 \\
Fluxes & 262 \\
Scurvy & 438 \\
Ulcers & 420 \\
Wounds and accidents & 389 \\
Rheumatism & 108 \\
Pulmonary inflammations & 92 \\
Intermittent fevers (for example, malaria) & 237 \\
Bilious fevers (that is, with associated bilious & 42 \\
vomiting) & 313 \\
Venereal diseases & 122 \\
Catarrhal fever (that is, associated with cough or & \\
phlegm) & 419 \\
Other & 3184 \\
Total &
\end{tabular}

ulcers were noted that were felt to be venereal in origin. These ulcers were found on the penis (33), in the throat (9), in the groin (5), on the legs (2), perineum (1), breast (1), all over the body (2) and in six cases the site was not specified. In 19 cases, general skin eruptions were described, this was also called venereal itch and described in one case as a honeycomb rash.

Able Seaman Jason Darling, 23, of HMS Albion was a typical case. ${ }^{7}$ He presented with chancres of the glans and prepuce and a swelling in the groin. These symptoms appeared 10 days after "seeing a girl" and now he was having difficulty walking. He was treated with lunar caustic, a mercury based ointment. Mercury, although widely used, was not without its side effects. Marine Private Thomas Cocksley, had been ill for 11 months when a new surgeon Thomas Eshelby arrived on HMS Seahorse. He had a venereal ulcer of the groin and fistula in ano but had taken too much mercury. Eshelby was forced to send him to Haslar Hospital to be cured. ${ }^{8}$ This problem was discussed by Dr Falck in The Seaman's Medical Instructor. He warned against the overuse of mercury. It was commonly given until it caused the patient to salivate. Falck warned that use of such high doses was "using mercury as a poison." ${ }^{\prime 9}$

Mr Parry, surgeon to HMS Adventure noted that chancre and buboes were always symptoms of the pox and should be treated with mercury but this should not be used with gonorrhoea. ${ }^{10}$ Gonorrhoea was treated with bed rest and a cooling regimen. This required not eating or drinking anything to inflame or heat the body such as wine, spices, onions, or meat. Instead sufferers were given barley water or milk. Northcote also warns against, "amorous dalliance with women, obscene books and whatever else inflames the fancy." ${ }^{\prime 11}$

Astringent injections of white vitriol (zinc sulphate) or barley water under the prepuce or down the urethra were also prescribed. Van de Burgh suggested half an ounce of a concoction of Epsom salts and sugar of lead, "to be injected down the yard [penis]". This was followed by one dram [there are eight drams to the ounce] of gum Arabic in three ounces of water if the scalding persisted. ${ }^{12}$

Outbreaks of venereal disease were common while the ship was in port. Sailors not only had the opportunity to visit the local women when on shore leave, but the women were commonly permitted on board. The Mariners Medical Guide suggests the sailors, "wash the nut of the yard [glans] with a soft sponge and yellow soap after coition" to prevent contracting a venereal infection. ${ }^{12}$

\section{PENILE PATHOLOGY}

The penile conditions described in the journals were often a consequence of venereal disease. There were 30 cases of phimosis of the prepuce and 19 cases of paraphimosis. In 14 cases, a diagnosis of chordee was made. Chordee was variously described as a hardening of the penile shaft or painful, sustained erection. This may represent either priapism or an inflammatory infiltration of the shaft. It was almost always associated with a venereal infection. One treatment was ointment of camphor in brandy and mercury and was obviously a very painful condition; a grain of opium was suggested at bedtime.

The preferred management of both phimosis and paraphimosis was medical; calomel or mercury ointment was commonly used and only rarely was surgery resorted to. John Burrows, the boatswains mate of HMS Seahorse, after failure of medical treatment, had the surgeon remove half an inch of prepuce for a venereal phimosis so severe that urine would scarcely pass. ${ }^{13}$ Able Seaman Duncan of HMS Acille had a phimosis so tight the surgeon could not pass even a small 


\begin{tabular}{|lll|}
\hline \multicolumn{2}{|l|}{ Table 2 Contemporary naval surgical textbooks } \\
\hline Author & Title & Year of publication \\
\hline John Atkins & The Navy Surgeon & 1742 \\
Solomon de Monchy & Usual diseases on voyages to the & 1762 \\
& West Indies & 1762 \\
James Lind & The Health of Seamen & 1770 \\
William Northcote & The Marine practice of Physic and & \\
& Surgery & 1774 \\
N.D Falck & The Seamans Medical Instructor & 1789 \\
Gilbert Blane & The Diseases of Seamen & 1797 \\
Thomas Trotter & Medicina Nautica & 1804 \\
Robert Robertson & Diseases incident to Seamen \\
C F Van de Burgh & The Mariners Medical Guide & 1819 \\
\hline & & \\
\end{tabular}

irrigation syringe into it. He however, "would not consent to be cut"; he remained on the sick list for two months. ${ }^{14}$

\section{SCROTAL PAIN AND SWELLING}

Many men complained of painful swollen testicles. Then, as now, in these young men, this often represented epididymitis secondary to sexually transmitted disease. There were 30 cases that presented with swollen testicles, 15 cases of hernia and 17 cases of hernia humoralis. The latter is a description of a reactive hydrocoele, after venereal orchitis. Treatment was with a bread and milk poultice, mercury, and a truss. ${ }^{11}$ This was differentiated from a vaginal hydrocoele, or dropsy of the scrotum, through which "the light of a candle could be seen". ${ }^{12}$

Scrotal swelling was a well recognised occupational hazard of sailors. It was particularly common in topmen (who worked in the high rigging), because of the trauma of sliding down the back stays (ropes running backwards from the mast to the deck level) or lying on the yards. ${ }^{12}$

Hernia, or rupture, was another common condition in sailors undertaking heavy manual labour. It could be serious in terms of morbidity but also could compromise a sailor's livelihood. An irreducible hernia was treated with warm baths and a grain of opium every eight hours coupled with attempts at reduction. If this failed, surgery was indicated; Van de Burgh warned a delay of 36 hours would lead to inevitable mortification and death! ${ }^{12}$ A sailor with a large or recurrent hernia had no place in a warship and these men were discharged from the service as unfit for duty.

Cases of swollen testicles were also seen after injection of chemicals up the urethra. Jason Hull, ship's cook and Jonathan Squire, seaman, both presented to the surgeon of HMS Albion with swollen testicles. They had attempted to cure themselves of venereal disease by injecting substances urethrally. ${ }^{15}$

There was a least one man who may have had a testicular cancer. Martin McDonald, a 32 year old landsman, gives a three year history of testicular problems after trauma to the scrotum. The surgeon, Charles Cudlipp, found the "epididymis and body of the testicle ... replaced by a sciccorous [sic] mass" and recommended removal of the organ. A schirrus was described as a hard, unequal tumour with little or no pain; it was a malignant tumour, which "admits but seldom of a cure". ${ }^{11}$ The mass could also have been calcified haematoma or tuberculous. Cudlipp, believing it to be malignant, did not attempt the orchidectomy himself but discharged the man from the service so he could find someone ashore to do this; "his only chance" writes the surgeon. ${ }^{16}$

\section{URINARY SYMPTOMS AND RETENTION}

Ardor urinae, or difficulty passing urine, was described in 23 patients. In 18 , the term dysuria was used, meaning pain on passing urine and once again was usually associated with venereal disease. There were 24 cases of urethral discharge; this was also called gleets or running and was a diagnostic symptom of gonorrhoeal infection. One man was described as having strangury, six had stoppage of water or urinary retention.

Difficulty in passing urine or strangury could have many causes. As detailed above it was often associated with the acute phase of venereal disease but episodes of bladder stone and ureteric colic can also cause strangury. Furthermore, Joseph Germain, a 52 year old seaman, presented in retention. The surgeon writes that this was "due to his time of life", making a diagnosis of benign prostatic hyperplasia.

\begin{tabular}{llll}
\multicolumn{3}{l}{ Table 3} & Description and complement of the ships \\
\hline Ship & Rate/type & Guns & Complement \\
\hline HMS Abercrombie & Frigate & 74 & 630 \\
HMS Abergavanny & 4th rate & 54 & 420 \\
HMS Aboukir & Frigate & 74 & 630 \\
HMS Achille & 3rd rate & 74 & 630 \\
HMS Adventure & 5th rate & 44 & 320 \\
HMS Ajax & 3rd rate & 74 & 630 \\
HMS Albion & Sloop & 22 & 160 \\
HMS Alfred & 3rd rate & 74 & 630 \\
HMS Alkmaar & 4th rate & 56 & 430 \\
HMS Ardent & 3rd rate & 64 & 525 \\
HMS Audacious & 3rd rate & 74 & 630 \\
HMS Etna & Bomb boat & 8 & 60 \\
HMS Seahorse & 5th rate & 38 & 230 \\
HMS Theseus & 4th rate & 74 & 630 \\
\hline
\end{tabular}


In five cases a diagnosis of urethral stricture was given Chronic gonococcal infection leads to stricture. Seaman Graham, a supernumary, presented with retention and a urethral bougie was passed enabling him to void. His ship, the Albion was anchored in the Thames making possible an early transfer to a nearby hospital ship. ${ }^{17}$

As well as bougies, the surgeon carried silver catheters (fig 3 ) and catheters of the rarer gum elastic, a comparatively new rubber like substance. These were used sparingly; medical treatments were always tried first such as hot baths or poultices. Able Seaman Owen Davies of HMS Alkmaar presented with lower abdominal pain and difficulty passing urine and was treated by blistering, a counter-irritant technique, the cups or vesicants being placed on the abdominal wall over the bladder and on the perineum. He was declared cured after five days. ${ }^{18}$

Benjamin Gagen was kicked in the groin and was unable to make water. At first he was treated with bleeding and clysters (another counter irritant), then warm baths and opioids. Finally Robert Tainish, the surgeon, declared "I considered this a proper time for the catheter". After nearly two months on the sick list he was discharged to the hospital. ${ }^{19}$ Marine James Bumford was also catheterised. He presented with abdominal pain, vertigo, vomiting, loss of vision and speech, and suppression of urine. The surgeon, Mr Loughlin, believed he and his three messmates had been poisoned. Loughlin passed a silver catheter relieving him of a pint of red fluid. ${ }^{14}$

The surgeons also had trocars to perform suprapubic catheterisation (fig 3). Drainage of the bladder was described by three routes in William Northcote's, The Marine Practice of Physic and Surgery. The puncture could be made above the os pubis, in the perineum or via the anus or vagina. ${ }^{11}$ The surgeon of HMS Alfred was unable to pass a bougie into Marine John Brimmer after an episode of blunt abdominal trauma. He therefore "perforated the bladder above the pubis and drew off $7 \frac{1}{2}$ pints of urine." ${ }^{20}$ Nevertheless, the marine subsequently died. Upon opening the body, the bladder was found to be inflamed and the scrotum and urethra were gangrenous. This suggests the cause of death was possibly by a process similar to Founier's gangrene.

\section{STONE DISEASE}

Stones in the bladder were of course well known. One sailor, James Williams, aged 50, was said to have a known stone. He presented while his ship, HMS Alfred, was stationed in the West Indies, with ardor urinae and passing urine like "soap suds". He was discharged ashore to Port Royal Hospital for treatment. ${ }^{21}$ The soap sud quality of his urine is an unusual

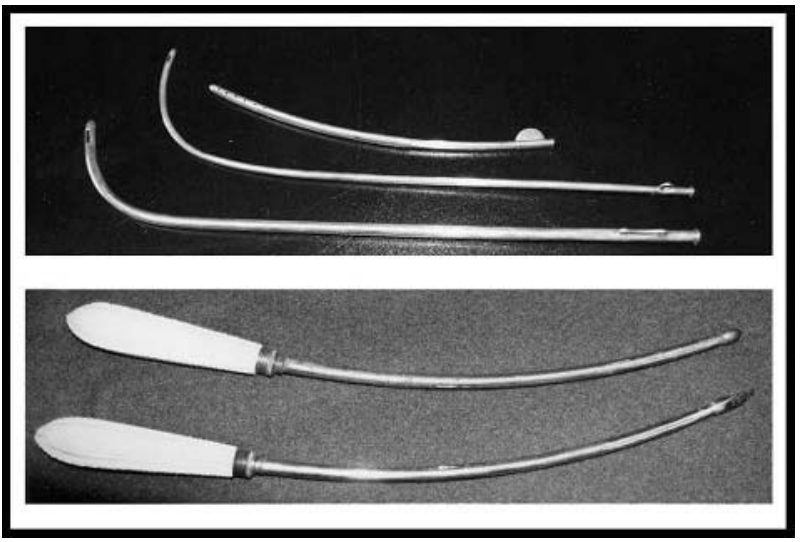

Figure 3 Silver catheters, above (author's collection). Trocars for suprapubic drainage (by permission of The Royal College of Surgeons of England). description and could also have been pneumaturia caused by vesicoenteric fistula. The only definitive treatment available at the end of the 18th century for bladder calculi was lithotomy or "cutting for the stone". Lithotomy was not common; understandably, it was avoided at all costs. Many less invasive treatments were tried first including poultices, application of hot flannels, cupping, blistering, and bleeding.

Stones described as "the gravel" appear in two cases. It was recognised even then, that smaller stones could form in the kidney and pass down the ureter presenting with colic. In five cases, a diagnosis of nephritis was given. Joseph Daykens, the tailor of HMS Albion, for example, presented with pain in the back, fevers, rigors, and with turbid urine containing sediment. His story is consistent with pyelonephritis. $^{7}$

A huge number of presentations to the surgeon in the journals are with abdominal pain. Although these are sometimes well described it was not often possible to make an attempt at a modern diagnosis. There were five cases however that did suggest a probable diagnosis of renal colic. For example, Marine Thomas Russel of HMS Alkmaar, presented with loin pain and testicular pain with no visible disease of the testicle. The pain was such it deprived him of his zest and appetite. He also complained of strangury. He was given opium for the pain and sent to the hospital ship. ${ }^{18}$

\section{TRAUMA}

Trauma to the external genitalia was also seen. This was unsurprising in this wooden world of constant manual labour. The sailing of these vessels was skilled work that required balance, timing, and strength and the ships were dangerous places to live and work. There were 22 cases of genitourinary trauma. These included contusions of the testicles in 12 cases, the loins in two, and the groin in two. A further three men were gored in the groin by a young bullock. It was not unusual for a living larder of animals to be kept aboard ship. One man, John Brimmer, sustained serious pelvic trauma, his case has been discussed above. One man was hit in the scrotum by a splinter and another by a pistol ball.

Michael Chris, a 28 year old sailor, (like many of his comrades) fell down a ladder joining decks and landed heavily on his perineum. The scrotum swelled to a huge size and, by the time he presented to the surgeon, had ulcerated. It was treated with bed (or rather hammock) rest and a scrotal support as well as a variety of poultices. He was discharged back to duty "well". ${ }^{19}$ Another sailor gave his surgeon a similar story hoping for an equally easy treatment however, the wry medic soon identified a venereal ulcer, and slapping on a venereal poultice, sent him to the hospital ship presumably for an unpleasant course of mercury. Patrick Wade of HMS Aboukir also sustained a contusion to his scrotum, he was also sent to the hospital, but this time, for leeches to bring down the swelling. ${ }^{22}$

Mr Francis Bazze, midshipman, was hit by a pistol ball while duelling in Cadiz. The ball entered the right thigh below the greater trochanter, passing through the leg it entered the scrotum. The surgeon dressed the wound and the patient recovered rapidly, he was in the sick bay for 39 days. The surgeon was careful to note that the young gentleman had suffered "no impediment in the action of the member". ${ }^{20}$

Splinter injuries were a major hazard during sea battles. A cannonball slicing through the wooden structure of the ship sent a deadly spray of oak splinters, some over a foot long, flying across the decks. Magnus Bloom was hit in the scrotum by a splinter during the Battle of Camperdown on 11 October 1797. Bloom was one of 90 wounded brought down to Robert Young, the surgeon of HMS Ardent, during the battle. He was one of the lucky ones who, "were conveyed on 
shore in good spirits cheering the ship ... smoking their pipes and jesting ... answering the cheers of thousands of the populace who received them at Yarmouth Key" three days later. ${ }^{23}$

\section{CONCLUSION}

This paper examines 446 cases of genitorurinary disease described in 39 Royal Navy surgeons' journals covering the period 8 December 1796 to 31 August 1810. Most cases (76\%) were directly attributable to venereal disease. The naval surgeons managed genitourinary diseases mainly medically. Preventative measures, conservative treatments, such as change in diet or activity, and drugs were all used. As a last resort, interventions such as urethral dilatation, catheterisation, suprapubic drainage, and open surgery were carried out.

Examination of these journals permits a glimpse of medical life in the Royal Navy during the time of Nelson. In particular, the case load and management of genitourinary disease shows the diversity of presentation to these surgeons. From the application of mercurial ointment to a venereal sore to the extraction of a splinter in the midst of a Napoleonic sea battle, the duties of the naval surgeon were varied indeed.

\section{REFERENCES}

1 Goddard JC. An insight into the life of Royal Naval surgeons during the Napoleonic war, part 1. J R Nav Med Serv 1991;77:205-22.

2 Goddard JC. An insight into the life of Royal Naval surgeons during the Napoleonic war, part 2. J R Nav Med Serv 1991;78:27-36

3 Cullen P. The journal of Peter Cullen 1769-1812. Greenwich: Library of The National Maritime Museum, 2/90 - IGR/22.

4 Goddard JC. The navy surgeon's chest: surgical instruments of the Royal Navy during the Napoleonic war. J R Soc Med 2004;97:191-7.

5 O'Neill R, ed. Patrick O'Brien's navy. London: Salamander Books, 2003.

6 Scott J. Medical journal of HMS Ajax, between 22nd June 1799 and 31 st January 1800, 1800; PRO ADM $10181 / 5$.
7 Watson JC. Medical journal of HMS Albion between 13th April 1799 and 2nd January 1801, 1801; PRO ADM 101 82/3.

8 Eshelby T. Medical journal of HMS Seahorse between 20th August 1797 and 20th August 1798. 1798; PRO ADM 101 120/6.

9 Falck ND. The seaman's medical instructor: in a course of lectures on accidents and diseases incident to seamen, in the various climates of the world; calculated for ships that carry no surgeon. London: Edward and Charles Dilly, 1774.

10 Parry D. Medical journal of HMS Adventure between 12th June 1799 and 20th April 1800, 1800; PRO ADM $10180 / 5$.

11 Northcote W. The marine practice of physic and surgery, including that in the hot countries, particularly useful to all who visit the East and West Indies, or the coast of Africa: to which is added, Pharmacopoeia marina, and some brief directions to be observed by the sea-surgeon in an engagement. London: $T$ Becket and P A de Hondt, 1777.

12 Van de Burgh CF. The mariner's medical guide. Comprising various diseases, with their general symptoms and most appropriate treatment, clearly and plainly stated, suitable to any capacity; also, the different causes and preventives of each depending upon change of climate. London: Baldwin Cradock, and Joy, Paternoster Row, 1819.

13 Eshelby T. Medical journal of HMS Seahorse between 21 st August 1799 and 18th August 1800, 1800; PRO ADM 101 120/6.

14 Laughlin BM. Medical journal of HMS Achille, between 23rd January 1800 and 21 st January 1801, 1801; PRO.ADM 101-80/4.

15 Allen S. Medical journal of HMS Albion between 4th April 1802 and 5th May 1802, 1802; PRO ADM101 82/3.

16 Cudlipp C. Medical journal of HMS Albion between 2nd December 1802 and 12th April 1803, 1803; PRO ADM 101 82/3.

17 Dingwell W. Medical journal of HMS Albion, between 31st May 1798 and 12th April 1799, 1799; PRO ADM 101 - 82/3.

18 McCully J. Medical journal of HMS Alkmaar between 14th December 1799 and 13th December 1800, 1800; PRO ADM 101 84/1.

19 Tainish R. Medical journal of HMS Theseus, between 19th August 1797 and 19th August 1798, 1798; PRO ADM 101 123/4.

20 Gray J. Medical journal of HMS Alfred, between 31 st August 1810 and 31 st August 1811, 1811; PRO ADM 101 - 83/4.

21 Warner W. Medical journal of HMS Alfred, between 1 st October 1797 and 31 st March 1798, 1798; PRO ADM 101 83/3.

22 McMillan J. Medical journal of HMS Aboukir, between 16th March 1808 and 15th March 1809, 1809; PRO ADM 101 80/3.

23 Young R. Medical journal of HMS Ardent between 29th March 1797 and 3rd April 1798, 1798; PRO ADM 101 85/7. 